\title{
PEMBENTUKAN PORTOFOLIO OPTIMAL BERDASARKAN MODEL INDEKS TUNGGAL PADA SAHAM INDEKS IDX30 DI BEI
}

\author{
Nyoman Candra Tri Wahyuni ${ }^{1}$ \\ Ni Putu Ayu Darmayanti
}

\author{
${ }^{12}$ Fakultas Ekonomi Dan Bisnis Universitas Udayana (Unud), Bali, Indonesia \\ e-mail: candratri763@gmailcom
}

\begin{abstract}
ABSTRAK
Mengetahui sekuritas yang masuk ke dalam penentuan portofolio optimal beserta dengan proporsi dari masing-masing saham serta untuk mengetahui besar return dan risiko portofolio yang diperoleh investor dikemudian hari.merupakan tujuan dari penelitian Penelitian dilakukan pada Indeks IDX30 di BEI periode Agustus 2016 - Januari 2018. Populasi penelitian ini menggunakan saham-saham yang tergabung dalam Indeks IDX30 dengan sampel sebanyak 25 saham Indeks IDX30 selama periode penelitian. Penelitian menggunakan model portofolio optimal, yaitu Model Indeks Tunggal. Hasil dari penelitian menunjukan dari 25 saham terdapat 8 saham yang dapat membentuk portofolio optimal dengan proporsinya masing-masing, yang terdiri dari saham ADRO, BBCA, BBNI, BBRI, BMRI, GGRM, PWON, dan UNTR. Saham-saham ini memberikan expected return portofolio sebesar 3,25 persen dengan tingkat risiko portofolio sebesar 0.07 persen.
\end{abstract}

Kata kunci: investasi saham, return, risiko, portofolio optimal, model indeks tunggal

\begin{abstract}
Stocks are included in determination of the optimal portfolio along with the proportion of each stock and to know how much portfolio return and risk investors will get in the future. The study was conducted on the IDX30 Index on the IDX for the period August 2016 January 2018. The population of this study used shares that were incorporated in IDX30 Index with sample used was 25 IDX30 Index stocks during the study period. The study uses the optimal portfolio model, namely the Single Index Model The results of the study show that from 25 stocks there are 8 stocks that can form an optimal portfolio with their respective proportions, consisting shares of ADRO, BBC, BBNI, BBRI, BMRI, GGRM, $P W O N$, and UNTR. These shares provide a portfolio expected return of 3.25 percent with a portfolio risk level of 0.07 percent.

Keywords : stock investment, return, risk, optimal portfolio, single index model
\end{abstract}




\section{PENDAHULUAN}

Investasi merupakan suatu bentuk pengelolaan modal yang dimiliki investor guna memberikan keuntungan di masa yang akan datang dengan cara menempatkan modal (dana) di saham, obligasi maupun reksa dana yang diperkirakan akan memberikan keuntungan bagi investor. Memperoleh keuntungan inilah yang merupakan perbedaan antara kegiatan investasi dengan kegiatan menabung untuk memberikan perlindungan dan rasa aman melalui tindakan berjaga-jaga dengan mencadangkan sejumlah danahal ini dikemukakan oleh Suroto (2015). Ramadhan (2014) mengemukakan bahwa pasar modal menyediakan berbagai macam investasi dengan masing-masing tingkat risiko yang tentunya berbeda-beda. Tingkat risiko yang berbeda ini disebabkan karena adanya pengaruh dari faktor internal maupun faktor eksternal yang sedang dihadapi oleh pihak perusahaan.

Tingkat pengembalian dibedakan menjadi dua jenis diantaranya tingkat pengembalian aktual (realisasi) serta tingkat pengembalian harapan. Tingkat pengembalian aktual dapat diperoleh dengan menghitung data historis atau data yang sudah ada sebelumnya, sedangkan tingkat pengembalian harapan nantinya akan diperoleh pada masa yang akan datang. Investor mendapatkan tingkat pengembalian dengan berinvestasi pada saham, investor juga akan dihadapkan dengan ketidakpastian tingkat pengembalian yang akan diperoleh. Ketidakpastian inilah yang disebut dengan tingkat risiko yang akan dihadapi oleh para investor apabila melakukan investasi.Penanaman modal juga merupakan suatu bentuk pengelolaan modal yang dimiliki investor guna memberikan keuntungan di masa 
yang akan datang dengan cara menempatkan modal (dana) di saham, obligasi maupun reksa dana yang diperkirakan akan memberikan keuntungan bagi investor.

Risiko sistematis atau sering disebut risiko pasar dalam pasar modal adalah risiko yang berkaitan dengan keaadan yang terjadi di pasar yang dapat berpengaruh terhadap variabilitas tingkat pengembalian penanaman modal. Risiko ini merupakan salah satu wujud risiko yang tidak bisa dihilangkan dengan cara diversifikasi (Tandellin, 2010:104). Risiko tidak sitematis merupakan risiko yang tidak ada hubungannya atas adanya perubahaan keadaan di pasar secara menyeluruh dan dapat diminimalisir dengan melakukan diversifikasi (Zubir, 2011;20). Menurut Triharjono (2013) mendifersikasikan beberapa kelas saham pada satu portofolio bisa menurunkan tingkat risiko yang diterima investor, dengan melakukan diversifikasi, investor akan mendapatkan risiko yang lebih kecil dibandingkan apabila investor mentransaksikan sahamnya pada satu aset saja.

Poornima \& Ramesh, A.P (2014) menyatakan portofolio bisa menjadi salah satu saran terbaik bagi investor yang ingin mengecilkan atau mendiversifikan risiko, dengan adanya portofolio, investor bisa memperoleh keuntungan (return) yang lebih besar daripada risiko yang diperoleh dimasa datang. Pembentukan portofolio merupakan suatu proses penggabungan dari beberapa kelas asset yang nantinya bisa menghasilkan return maksimal dengan risiko yang minimum. Pembentukan portofolio merupakan suatu penanaman modal berupa kombinasi dari beberapa surat yang dilakukan pada beberapa kelas asset sehingga 
memperoleh return atau tingkat pengembalian yang optimal dengan tingkat risiko tertentu, hal tersebut dikemukakan oleh Meman (2015) dan Darmitha \&I.B Anom Purbawangsa(2016).

Pembentukan suatu portofolio dapat menggunakan beberapa model pendekatan portofolio yaitu Model Indeks Tunggal serta Model Markowitz. Markowitz memang membantu untuk menghitung tingkat pengembalian harapandan risiko portofolio, namun menggunakan perhitungan yang lebih rumit dibandingkan dengan Model Indeks Tunggal pendapat tersebut dikemukakan oleh Mary \& Rathika, G (2015). Investor biasanya lebih banyak memakai teknik Model Indeks Tunggal dalam membuat portofolio optimal, hal ini dikarenakan teknik ini dirasa lebih gampang dari teknik Markowitz. Menurut Ariasih \& I Ketut Mustanda (2018), model perhitungannya lebih sedikit, dan juga sangat memperhatikan keadaan pasar dari return dan risiko yang diharapkan. Teknik perhitungan Model Indeks Tunggal juga memperlihatkan adanya hubungan antara sekuritas dengan perubahan harga pasar. Hal ini dapat dilihat ketika kondisi pasar yang dapat dilihat dari indeks pasar yang membaik maka nilai harga sahamnya bisa meningkat, sebaliknya apabila kondisi pasar memburuk maka nilai harga saham juga menurun (Hartono,2016:339).

Penelitian yang dilakukan oleh Andrade (2012) menghasilkan bahwa portofolio optimal dibentuk dari 5 saham perusahaan. Berdasarkan hasil penelitian yang dilakukan Gautam \& Singh, S(2014)menunjukkan dari 10 perusahaan perbankan yang diambil untuk penelitian, 2 perusahaan saja yang dapat membentuk portofolio optimal. Utamayasa \& Ni Luh Putu Wiagustini (2016) 
dalam penelitiannya yang dilakukan terdapat 2 saham perbankan yang bisa membentuk portofolio optimal dari 28 saham perbankan yang diteliti. Penelitian yang dilakukan pada indeks BSE SENSEX tentang portofolio optimal oleh Kumar (2013) memperoleh hasil 3 saham yang mampu membentuk portofolio optimal. Syamni \& Al Muntasir (2013) meneliti tentang portofolio optimal di Indeks LQ45 mendapatkan 8 saham yang dapat membentuk portofolio optimal dari 29 sampel saham yang digunakan.

Giri \&Gayadar Parhi (2017) dalam penelitiannya membentuk portofolio optimal dengan 50 sekuritas didapatkan bahwa terdapat 5 sekuritas yang bisa membentuk portofolio optimal. Penelitian yang dilakukan oleh Raju \&MrunaliJambotkar (2018) yang berjudul "Optimal portfolio construction in stock markets: Evidence from Indian Blue Chip Stocks" mendapatkan hasil bahwa terdapat 9 saham yang dapat membentuk portofolio optimal dari 20 saham yang digunakan dalam penelitiannya. Wibowo et al. (2014) dari 22 sampel saham perusahaan terpilih terdapat 14 saham perusahaan yang membentuk komposisi portofolio optimal. Penelitian yang dilakukan oleh Nandan \&Nivedita Srivastava (2017) tentang pembentukan portofolio optimal menggunakan Model Indeks Tunggal di Nifty 50 stocks memperoleh hasil dari 50 saham yang digunakan dalam penlitiannya menghasilkan 24 saham yang digunakan untuk membentuk portofolio optimal. Menurut Shah (2014) yang melakukan penelitian pada indeks CNX NSE di India mendapatkan hasil berupa 2 saham yang dapat membentuk portofolio optimal dari 50 saham yang digunakan. 
Subashree \&Bhoopal, M (2017) dalam penelitiannya yang berjudul pembentukan portofolio optimal dengan menggunakan Model Indeks Tunggal (Studi kasus pada sektor bank dan automobile) memperoleh hasil bahwa dari 10 saham pada sektor bank dan automobile yang digunakan dalam penelitiannya, terdapat 3 saham yang dapat membentuk sebuah portofolio optimal. Supriyanthi \& Henny Rahyuda (2017) menyatakan bahwa dari 16 saham anggota di Indeks Bisnis 27 yang digunakan untuk pembentukan portofolio optimal, terdapat 4 sekuritas yang dapat membentuk portofolio. Shah (2015) meneliti tentang membentuk portofolio optimal di 15 saham BSE menggunakan Model Indeks Tunggal serta CAPM memperoleh hasil bahwa dari 15 saham yang digunakan menunjukkan hasil bahwa 5 saham yang dapat membentuk sebuah portofolio optimal. Penelitian Nalini (2014) tentang portofolio optimal dengan model indeks tunggal pada Indeks BSE di India memperoleh hasil bahwa terdapat 4 sekuritas yang bisa membentuk portofolio optimal dari 15 sampel yang digunakan.

Saham-Saham yang tergabung dalam Indeks IDX30 digunakan dalam penelitian ini. Indeks IDX30 adalah salah satu indeks yang memiliki 30 saham dengan kepemilikan saham (Kapitalisasi) terbesar di Indeks LQ45. Pada tanggal 23 April 2012 BEI menerbitkan Indeks IDX30. Pemilihan saham dalam indeks ini dilakukan pada bulan Januari dan Juli. Jumlah sekuritas Indeks IDX30 yang terdiri dari 30 saham memiliki keunggulan lebih mudah dilakukan replika sebagai acuan portofolio (IDX Newsletter 2016).

Rumusan masalah dalam penelitian ini terdiri atas 1) Saham-Saham dalam Indeks IDX30 mana saja yang bisa membentuk sebuah portofolio optimal dan 
berapa besar proporsi dana yang dihasilkan oleh saham-saham pembentuk portofolio optimal? (2) Berapa besar return ekspetasi serta risiko portofolio yang diperoleh investor dari pembentukan portofolio optimal ini? (1) Untuk mengetahui sekuritas apa saja yang bisa membentuk sebuah portofolio dan besarnya bagian dana yang disumbangkanmasing-masing sahampembentuk portofolio optimal dalam Indeks IDX30 (2) Untuk mengetahui besarnya return ekspetasi dan risiko yang dihasilkan oleh saham dari pembentukan portofolio. Beberapa hal yang dijelaskan tadi merupakan tujuan dari penelitian ini.

Kegunaan penelitian ini yaitu diharapkan mampu menambah ilmu pengetahuan pembaca mengenai portofolio optimal menggunakan model indeks tunggal dan juga bisa dijadikan acuan ilmiah untuk kepentingan akademis serta penelitiannya berikutnya. Kegunaan praktis yang diperoleh yaitu dapat menyediakan beberapa pertimbangan serta gambaran untuk para investor dalam pengambilan keputusan apabila ingin berinvestasi dengan membentuk sebuah portofolio

Investasi merupakan penundaan konsumsi pada saat ini untuk digunakan dalam produksi efisien selama beberapa periode waktu tertentu, dengan maksud bahwa penanaman modal ini dilakukan dengan adanya pengorbanan konsumsi yang nantinya dari pengorbanan tersebut diharapkan bisa mendapatkan keuntungan di masa depan (Hartono, 2016:5). Portofolio merupakan beberapa kumpulan aset investasi, baik berupa aset nyata maupun aset keuangan. Portofolio menjelaskan bagaimana melakukan pemilihan dari sekian banyak sekuritas yang 
ada untuk dapat meminimalkan risiko yang akan dihadapi dan mendapatkan return yang semaksimal mungkin.

Portofolio dapat disimpulkan sebagai gabungan dari beberapa sekuritas yang bertujuan untuk menghasilkan kombinasi efisen sehingga bisa memenuhi tujuan investor untuk memperoleh return yang tinggi dan memperkecil risiko yang akan diterima dikemudian hari. Portofolio optimal memiliki kombinasi dimana return ekspetasi dengan risiko terbaik. Tujuan utama dari pemilihan portofolio adalah mengelompokkan dan membentuk portofolio dengan expected return yang maksimun dengan karekteristik tingkat risiko tertentu.

Return adalah sebuah tingkat pengembalian (imbalan) yang akan diterima investor atas beban risiko yang ditanggung dalam sebuah investasi yang sudah terjadi (return realisasi) ataupun yang diharapkan bisa didapatkan pada masa mendatang (return ekspetasi). Return ekspetasi merupakan rata-rata tertimbang dari seluruh return yang terdapat pada sekuritas tunggal dalam suatu portofolio. Return realisasi portofolio adalah rata-rata tertimbang berdasarkan seluruh return realisasi masing-masing sekuritas tunggal yang berada dalam portofolio tersebut. Risiko merupakan suatu konsekuensi yang akan diterima investor di masa datang pada saat memilih melakukan sebuah investasi.

Menurut Hartono (2016:313) risiko portofolio bukan merupakan rata rata tertimbang dari seluruh risiko sekuritas tunggal, sedangkan return merupakan rata-rata tertimbang dari seluruh return sekuritas tunggal. Risiko portofolio dapat dihitung dengan besarnya deviasi standar atau varian dari nilainilai return sekuritas-sekuritas tunggal yang ada di dalamnya. Menurut 
Nyoman Candra Tri Wahyuni, Pembentukan Portofolio Optimal....

Gunawan \& Luh GedeSri Artini (2016) dalam penelitiannya menemukan bahwa risiko portofolio tidak dapat dihitung hanya dengan menjumlahkan masing-masing risiko saham yang terdapat dalam suatu portofolio. Risiko sangat erat kaitannya dengan return, jadi sebaiknya para investor sebelum berinvestasi agar mempertimbangkan tingkat risikonya juga agar tingkat return yang diharapkan investor dapat tercapai menurut Tripathy (2011).

Rahmasita et al. (2014) menyatakan bahwa membentuk sebuah portofolio merupakan sebuah cara yang digunakan investor untuk memperoleh tingkat pengembalian maksimum dengan tingkat risiko tertentu. Model Indeks Tunggal dan Markowitz merupakan beberapa model yang dapat digunakan investor dalam membentuk portofolio. Tandellin (2010:133) menjelaskan asumsi yang dipakai dalam Model Indeks Tunggal adalah bahwa sekuritas akan berkorelasi hanya jika sekuritas-sekuritas tersebut mempunyai respons yang sama terhadap return pasar. Hal tersebut dapat dilihat apabila kondisi pasar yang ditunjukkan oleh suatu indeks pasar memburuk, maka nantinya nilai harga suatu saham juga akan ikut menurut Agmiviolya et al. (2014) dan Qur'anitasari et al. (2016). Tingkat pengembalian sekuritas akan berkolerasi karena adanya gerakan umum di indeks sekuritas terhadap perubahan - perubahan nilai indeks (Gopalakrishnan, 2014).

Teknik awal dalam portofolio optimal Model Indeks Tunggal dilakukan dengan cara menghitung return-return saham individual, dilanjutkan dengan menghitung varian saham dan pasar. Langkah selanjutnya mencari nilai ERB masing-masing sekuritas dan menyusun peringkat ERB dari yang terbesar hingga ke yang terendah. Setelah itu dilanjutkan dengan menghitung nilai $\mathrm{Ci}$ atau $\mathrm{Cut}$-Off 
Rate dan membandingkan dengan nilai ERB. Apabila hasil perhitungan ERB $\geq \mathrm{Ci}$, maka saham tersebut dapat dimasukkan kedalam portofolio optimal. Sedangkan apabila $\mathrm{ERB} \leq \mathrm{Ci}$ maka saham tersebut belum tergolong saham yang dapat dibentuk portofolio optimal.

\section{METODE PENELITIAN}

Pendekatan kuantitatif yang berbentuk deskriptif merupakan desain dalam penelitian ini dengan tujuan untuk mengetahui saham-saham yang layak untuk dimasukkan ke dalam portofolio optimal. returnportofolio, dan risiko portofolio merupakan variable yang akan diteliti dalam penelitian ini. Lokasi yang digunakan yaitu Indeks IDX30 di BEI. Seluruh saham yang terdaftar pada Indeks IDX30 selama periode penelitian yaitu Agustus 2016-Januari 2018 merupakan populasi yang digunakan dalam penelitian ini.

Penelitian ini menggunakan 25 saham perusahaan yang dipilih dengan metode purposive sampling yang memiliki kriteria, saham yang muncul secara terus-menerus dan merupakan saham tetap selama periode penelitian yaitu Agustus 2016-Januari 2018.Data yang digunakan dalam penelitian ini ada 2 yaitu data kuantitatif dan kualitatif. Data kuantitaif dalam penelitian ini adalah Data closing price saham dan Indeks IDX30, serta data tingkat suku bunga SBI.

Menurut Hartono (2016:429) analisis portofolio optimal dapat dilakukan dengan langkah - langkah sebagai berikut:

Menghitung Return Realisasi Saham (Tingkat Pengembalian Saham)

Tingkat pengembalian saham merupakan selisih harga saham saat ini dengan harga saham sebelumnya. Rumus untuk menghitung Return saham individu (Hartono, 2016:265): 
Rit $=\frac{P-P[-1}{P-1}$

Keterangan:

$\mathrm{R}_{\mathrm{it}} \quad=$ Tingkat pengembalian sekuritas pada peiode $\mathrm{t}$

$\mathrm{P}_{\mathrm{it}} \quad=$ Harga sekuritas pada periode $\mathrm{t}$

$\mathrm{P}_{\mathrm{it}-1} \quad=$ Harga sekuritas pada periode $\mathrm{t}-1$

Menghitung Return Ekspetasi Saham

Return ekspetasi saham merupakan tingkat pengembalian yang ingin didapatkan investor dengan menghitung rata - rata return realisasi saham. Berikut ini merupakan rumus dari Expected return (Zubir, 2011:5):

$\mathrm{E}(\mathrm{Ri})=\frac{\sum_{t=1}^{n} R}{n}$

Keterangan:

$\mathrm{E}\left(\mathrm{R}_{\mathrm{i}}\right)=$ Tingkat pengembalian harapan pada saham $\mathrm{i}$

$\mathrm{R}_{\mathrm{it}} \quad=$ Tingkat pengembalian sekuritas $\mathrm{i}$ pada periode $\mathrm{t}$

$\mathrm{N} \quad=$ Jumlah periode pengamatan

Return Pasar

Return pasar merupakan seberapa besar tingkat pengembalian yang diperoleh investor pada seluruh saham yang tercermin dari Indeks IDX30. Return Pasar dapat dihitung dengan rumus berikut (Hartono, 2016:408):

$\mathrm{Rm}=\frac{n 3_{[-l l} 3_{[-1}}{l l 3_{[-1}}$

Keterangan :

$\mathrm{R}_{\mathrm{III}} \quad=$ tingkat pengembalian indeks IDX30

IDX30 $\quad=$ indeks IDX30 periode $\mathrm{t}$

$\mathrm{IDX} \mathrm{t}_{\mathrm{t}-1} \quad=$ indeks IDX30 sebelum periode

Menghitung risiko pasar

Selisih antara risiko pasar pada hari ke $\mathrm{t}$ dengan expected return pasar kemudian dibagi dengan jumlah periode pengamatan sebelumnya merupakan 
carauntuk mencari nilai dari risiko indeks IDX30. Nilai risiko indeks dapat dihitung dengan rumus :

$\sigma_{m}^{2}=\sum_{t=1}^{n} \frac{K-E(K)}{n-1}$.

Keterangan :

$\sigma_{m}^{2} \quad=$ varian Indeks IDX30

$\mathrm{Rm}_{\mathrm{t}} \quad=$ tingkat pengembalian Indeks pada hari ke $\mathrm{t}$

$\mathrm{E}(\mathrm{Rm})=$ tingkat pengembalian Indeks yang diharapkan

$\mathrm{n} \quad=$ banyaknya pengamatan yang dilakukan

Menghitung nilai beta

Beta merupakan koefisien dengan fungsi yaitu untuk menhitung adakah pengaruh tingkat pengembalian pasar terhadap perubahan tingkat pengembalian saham yang digunakan. Beta dapat dihitung dengan rumus

$\beta=\frac{\left[n \cdot \sum\left(\begin{array}{lll}k & . R & )\end{array}-\left(\begin{array}{ll}\sum R & \cdot \sum R\end{array}\right)\right.\right.}{n \cdot\left(\sum R{ }^{2}\right) \cdot\left(\sum R r^{2}\right)}$

Keterangan :

$\beta=$ Beta

$\mathrm{n} \quad=$ Periode / Jumlah data

Rmt $=$ Tingkat pengembalian Indeks

Rit $\quad=$ Tingkat pengembalian Sekuritas

Menghitung nilai alpha

Koefisien alpha merupakan koefisien yang menunjukkan sebuah bagian return saham yang cukup unik. Alpha dapat dihitung dengan cara

$\alpha=\mathrm{E}(\mathrm{Ri})-(\beta . \mathrm{E}(\mathrm{Rm}))$

Keterangan :

$\alpha \mathrm{i} \quad=$ alpha sekuritas

$\mathrm{E}(\mathrm{Ri})=$ tingkat pengembalian harapan sekuritas

$\mathrm{Rm} \quad=$ tingkat pengembalian indeks

Menghitung varian dari kesalahan residu 
Varians residual adalah variabel yang menunjukkan besarnya risiko tidak sistematis yang terjadi pada perusahaan. Varians residuals dapat dihitung menggunakan rumus.

$\sigma_{e}^{2}=\mathrm{R}_{\mathrm{i}}-\left[\alpha_{\mathrm{i}}+\beta_{\mathrm{i}}\left(\mathrm{R}_{\mathrm{mt}}\right)\right]$

Keterangan :

$\sigma_{e}^{2} \quad=$ varians dari kesalahan residu

$\sigma_{i} \quad=$ varians sekuritas $\mathrm{i}$

$\beta_{l} \quad=$ beta sekuritas

$\sigma_{m} \quad=$ varians tingkat pengembalian indeks

Menghitung Excess Return to Beta (ERB)

Menggunakan suku bunga SBI periode Agustus 2016 sampai Januari 2018 merupakan data yang digunakan untuk menghitung ERB. Excess return to beta ratio (ERB) adalah selisih ukuran return ekspetasi terhadap return aktiva bebas risiko yang dibagi dengan Beta.

$\mathrm{ERB}_{\mathrm{t}}=\frac{E(K)-R}{\beta_{\mathrm{E}}}$

Keterangan :

$E$, excess return to beta sekuritas ke-i

$E\left(K_{l}\right)=$ tingkat pengembalian harapan berdasarkan model indeks ganda untuk sekuritas ke-i

$K_{B} \quad=$ tingkat pengembalianaktiva bebas risiko menggunakan Sertifikat Bank Indonesia (SBI)

$\beta_{l} \quad=$ Beta saham ke-i

Menghitung cut-off (Ci)

Ci merupakan titik pembatas yang digunakan agar bisa menentukan apakah suatu saham yang dipilih untuk membentuk portofolio optimal dapat dimasukkan atau tidak. Berikut rumus yang dapat digunakan untuk menghitung $\mathrm{Ci}$ (Hartono, 2016:431): 
$\mathrm{Ci}=\frac{\sigma^{2} \cdot \sum_{j-1}^{L} A}{1+\sigma^{2} \cdot \sum_{j=1}^{L} B}$

Menghitung besarnya proporsi saham

Mencari besarnya bagian yang disumbangkan sekuritas ke-i untuk dapat membentuk portofolio. Berikut rumus yang digunakan:

$\mathrm{Wi}=\frac{Z}{\sum_{j-l}^{K} Z}$, dan nilai Xi sebesar, $\mathrm{Zi}=\frac{\beta_{\mathrm{l}}}{u_{e}^{z}}\left(\mathrm{ERB}-\mathrm{C}^{*}\right)$

Menghitung tingkat pengembalianharapan dan risiko portofolio optimal.

Tingkat Pengembalian Portofolio

Tingkat pengembalian harapan portofolio merupakan suatu rata-rata tertimbang dari beberapa return ekspektasi masing - masing sekuritas tunggal di dalam portofolio. Risiko Portofolio adalah perbedaan return aktual dengan return harapan.

$\mathrm{E}(\mathrm{Rp})=\alpha_{\mathrm{p}}+\left(\beta_{\mathrm{p}} \cdot \mathrm{E}(\mathrm{Rm})\right.$

Keterangan :

$\mathrm{E}\left(\mathrm{R}_{\mathrm{p}}\right)=$ tingkat pengembalian harapan (expected return)portofolio

$\alpha_{\mathrm{p}} \quad=$ rata-rata tertimbang dari alpha setiap sekuritas

$\beta_{\mathrm{p}} \quad$ = rata-rata tertimbang dari beta setiap sekuritas

Risiko Portofolio

Risiko Portofolio adalah perbedaan return aktual dengan return harapan.

Risiko Portofolio dapat dihitung dengan menggunakan rumus

$\sigma \mathrm{p}^{2}=\left[\sum_{t=1}^{n} W \cdot \beta\right]^{2} \cdot \sigma_{M}^{2}+\left[\sum_{t=1}^{n} W \cdot \sigma_{e}\right]^{2}$

Keterangan :

$\sigma \mathrm{p}^{2}=$ risiko portofolio

$\mathrm{W}_{\mathbf{1}} \quad=$ proporsi sekuritas

$\beta_{1} \quad=$ beta yang mengukur koefisien yang mengukur perubahan

$\mathrm{Ri}$ akibat dari perbedaan $\mathrm{Rm}$

$\sigma_{\mathrm{e}} \quad=$ varian residu 
$\sigma_{\mathrm{m}}^{2} \quad=$ varian pasar

\section{HASIL DAN PEMBAHASAN}

Hasil penelitian ini memuat tentang tata cara bagaimana peneliti bisa memperoleh saham Indeks IDX30 yang menjadi sampel penelitian untuk dapat membentuk sebuah portofolio optimal dengan menggunakan pendekatan Single Indexs Model. Proses membentuk sebuah portofolio optimal berdasarkan Model Indeks Tunggal dapat dilakukan dengan tahapan-tahapan yaituReturn realisasiserta return ekspetasimasing-masing saham.

Tahap pertama adalah menghitung masing-masing return saham (realisasi maupun ekspetasi) yang tergabung dalam Indeks IDX30 periode Agustus 2016Januari 2018 dan juga digunakan sebagai sampel penelitian. Hasil dari perhitungan return saham realisasi dapat diperoleh dari mengurangi harga saham saat ini dengan harga saham sebelumnya dibagi dengan harga saham sebelumnya. Return saham ekspetasi dapat dihitung menggunakan rata-rata nilai hitung return realisasi. Hasil dari perhitungan return realisasi dan return ekspetasi dapat dilihat pada Tabel 1. 
Tabel 1.

Return Realisasi dan Return Ekspetasi Saham Indeks IDX30

\begin{tabular}{clccclcc}
\hline No & $\begin{array}{c}\text { Kode } \\
\text { Saham }\end{array}$ & LRit & E(Ri) & No & $\begin{array}{c}\text { Kode } \\
\text { Saham }\end{array}$ & Rit & E(Ri) \\
\hline 1 & ADHI & -0.1115 & -0.0066 & 14 & KLBF & -0.05371 & -0.00316 \\
2 & ADRO & 0.8739 & 0.0514 & 15 & LPKR & -0.60711 & -0.03571 \\
3 & ASII & 0.0611 & 0.0036 & 16 & LPPF & -0.4780 & -0.0281 \\
4 & BBCA & 0.4342 & 0.0255 & 17 & MNCN & -0.1390 & -0.0082 \\
5 & BBNI & 0.5156 & 0.0303 & 18 & PGAS & 0.0237 & 0.0014 \\
6 & BBRI & 0.4939 & 0.0291 & 19 & PWON & 0.2317 & 0.0136 \\
7 & BMRI & 0.3972 & 0.0234 & 20 & SMGR & 0.1578 & 0.0093 \\
8 & BSDE & -0.1302 & -0.0077 & 21 & SSMS & -0.0767 & -0.0045 \\
9 & GGRM & 0.2634 & 0.0155 & 22 & TLKM & -0.0211 & -0.0012 \\
10 & HMSP & 0.2270 & 0.0134 & 23 & UNTR & 0.7807 & 0.0459 \\
11 & ICBP & -0.12103 & -0.00712 & 24 & UNVR & 0.1956 & 0.0115 \\
12 & INDF & 0.00029 & 0.00002 & 25 & WSKT & 0.0959 & 0.0056 \\
13 & INTP & 0.28050 & 0.01650 & & & & \\
\hline
\end{tabular}

Sumber: Data sekunder diolah, 2018

Berdasarkan hasil perhitungan return pada Tabel 1, dapat dilihat bahwa return ekspetasi tertinggi diraih oleh saham Adaro Energy Tbk (ADRO), sedangkan nilai return terkecil diperoleh oleh saham Lippo Karawaci Tbk (LPKR).

Nilai Excess Return to Beta (ERB)

Menghitung ERB dapat dilakukan dengan mengurangi tingkat pengembalianmasing-masing sekuritas dengan tingkat bunga bebas risiko, sehingga mendapatkan hasil yang kemudian dibagi dengan beta sekuritas. Berikut tabel perhitungan nilai Excess Return to Beta (ERB).

Tabel 2. Dapat dilihat bahwa aset yang memiliki nilai ERB yang paling tinggi adalah saham United Tractors Tbk. (UNTR) dengan nilai ERB sebesar 
Nyoman Candra Tri Wahyuni, Pembentukan Portofolio Optimal....

0.09204, sedangkan ERB dengan nilai yang terkecil sebesar -0.03075 yang diperoleh oleh saham Matahari Department Store Tbk. (LPPF).

Tabel 2.

Tingkat Pengembalian Harapandan Excess Return to Beta

\begin{tabular}{|c|c|c|c|c|}
\hline No & Kode Saham & Nama Saham & $\mathbf{E}(\mathbf{R i})$ & $\operatorname{ERB}(\mathbf{i})$ \\
\hline 1 & ADHI & Adi Karya (Persero) Tbk & -0.00656 & -0.00942 \\
\hline 2 & ADRO & Adaro Energy Tbk & 0.05140 & 0.08031 \\
\hline 3 & ASII & Astra Internasional Tbk & 0.00359 & -0.00027 \\
\hline 4 & $\mathrm{BBCA}$ & Bank Central Asia (Persero) Tbk & 0.02554 & 0.02237 \\
\hline 5 & $\mathrm{BBNI}$ & $\begin{array}{l}\text { Bank Negara Indonesia (Persero) } \\
\text { Tbk }\end{array}$ & 0.03033 & 0.01891 \\
\hline 6 & BBRI & $\begin{array}{l}\text { Bank Rakyat Indonesia (Persero) } \\
\text { Tbk }\end{array}$ & 0.02905 & 0.01767 \\
\hline 7 & BMRI & Bank Mandiri (Persero) Tbk & 0.02336 & 0.01906 \\
\hline 8 & BSDE & Bumi Serpong Damai Tbk & -0.00766 & -0.00865 \\
\hline 9 & GGRM & Gudang Garam Tbk & 0.01549 & 0.01431 \\
\hline 10 & HMSP & $\begin{array}{l}\text { Hanjaya Mandala Sampoerna } \\
\text { Tbk }\end{array}$ & 0.01336 & 0.01023 \\
\hline 11 & ICBP & $\begin{array}{l}\text { Indofood CBP Sukses Makmur } \\
\text { Tbk }\end{array}$ & -0.00712 & -0.01460 \\
\hline 12 & INDF & Indofood Sukses Makmur Tbk & 0.00002 & -0.00442 \\
\hline 13 & INTP & $\begin{array}{l}\text { Inducement Tunggal Prakarsa } \\
\text { Tbk }\end{array}$ & 0.01650 & 0.00960 \\
\hline 14 & KLBF & Kalbe Farma Tbk & -0.00316 & -0.00663 \\
\hline 15 & LPKR & Lippo Karawaci Tbk & -0.03571 & -0.20190 \\
\hline 16 & LPPF & Matahari Department Store Tbk & -0.02812 & -0.03075 \\
\hline 17 & MNCN & Media Nusantara Citra Tbk & -0.00818 & -0.01455 \\
\hline 18 & PGAS & $\begin{array}{l}\text { Perusahaan Gas Negara (Persero) } \\
\text { Tbk }\end{array}$ & 0.00139 & -0.00987 \\
\hline 19 & PWON & Pakuwon Jati Tbk & 0.01363 & 0.02400 \\
\hline 20 & SMGR & Semen Indonesia (Persero) Tbk & 0.00928 & 0.00585 \\
\hline 21 & SSMS & Sawit Sumbermas Sarana Tbk & -0.00451 & -0.01359 \\
\hline 22 & TLKM & $\begin{array}{l}\text { Telekomunikasi Indonesia } \\
\text { (Persero) Tbk }\end{array}$ & -0.00124 & -0.00514 \\
\hline 23 & UNTR & United Tractors Tbk & 0.04592 & 0.09204 \\
\hline 24 & UNVR & Unilever Indonesia Tbk & 0.01151 & 0.00717 \\
\hline 25 & WSKT & Waskita Karya (Persero) Tbk & 0.00564 & 0.00350 \\
\hline
\end{tabular}

Sumber: Data sekunder diolah, 2018

Nilai Cut-Off Rate dan Cut-OffPoint (Ci dan C*) 
Tahap ketiga yaitu mencarinilai dari $\mathrm{Cid}$ an $\mathrm{C}^{*}$.Ci merupakan nilai pembatas yang digunakan agar bisa menentukan apakah suatu saham yang dipilih untuk membentuk portofolio optimal dapat dimasukkan atau tidak.Nilai pembatas ini digunakan untuk menentukan titik potong yang menunjukkan saham mana saja yang dapat memebentuk sebuah portofolio optimal atau tidak. Mencari titik potong dapat dilakukan dengan menghitung nilai $\mathrm{Ci}$ terlebih dahulu, namun sebelum mendapatkan nilai $\mathrm{Ci}$ perhitungannya diawali dengan mencari nilai $\mathrm{Ai}$ dan Bi terlebih dahulu. Setelah diperoleh nilai Ai dan Bi kemudian dihitung nilai $\mathrm{Ci}$ yang dimana nantinya nilai $\mathrm{Ci}$ ini akan menjadi titik potong atau Cut-OffPoint $\left(\mathrm{C}^{*}\right)$. Nilai Cut-OffPoint $\left(\mathrm{C}^{*}\right)$ didapatkan dengan cara memilih nilai $\mathrm{Ci}$ yang terbesar. Hasil perhitungan Ci dapat dilihat pada tabel 3.

Berdasarkan hasil perhitungan nilai CI dan $\mathrm{C}^{*}$ dapat dilihat pada Tabel 3. menunjukkan bahwa hasil perhitungan $\mathrm{Ci}$ terbesar dari beberapa saham yang masuk kedalam sampel penelitian jatuh pada saham Bank Negara Indonesia Tbk (BBNI) sebesar 0.0127 sehingga nilai cut-off point sekuritas yang membentuk portofolio optimal adalah sebesar 0.0127 . 
Tabel 3.

Cut-Off Rate dan Cut-OffPoint Saham Indeks IDX30

\begin{tabular}{clcccccc}
\hline No & Kode Saham & ERBi & $\mathbf{A i}$ & $\mathbf{B i}$ & $\boldsymbol{\sigma \mathbf { M } ^ { \mathbf { 2 } }}$ & $\mathbf{C i}$ & $\mathbf{C}^{*}$ \\
\hline 1 & ADHI & -0.0094 & -1.6250 & 172.539 & 0.0011 & -0.0015 & \\
2 & ADRO & 0.0803 & 2.0667 & 25.734 & 0.0011 & 0.0022 & \\
3 & ASII & -0.0003 & -0.2150 & 799.804 & 0.0011 & -0.0001 & \\
4 & BBCA & 0.0224 & 19.6454 & 878.116 & 0.0011 & 0.0110 & \\
5 & BBNI & 0.0189 & 12.4298 & 657.462 & 0.0011 & 0.0079 & \\
6 & BBRI & 0.0177 & 41.2790 & 2336.657 & 0.0011 & 0.0127 & C $^{*}$ \\
7 & BMRI & 0.0191 & 15.2248 & 798.609 & 0.0011 & 0.0089 & \\
8 & BSDE & -0.0087 & -7.7771 & 898.649 & 0.0011 & -0.0043 & \\
9 & GGRM & 0.0143 & 2.8701 & 200.612 & 0.0011 & 0.0026 & \\
10 & HMSP & 0.0102 & 6.5781 & 642.886 & 0.0011 & 0.0042 & \\
11 & ICBP & -0.0146 & -9.2355 & 632.548 & 0.0011 & -0.0060 & \\
12 & INDF & -0.0044 & -1.7534 & 396.339 & 0.0011 & -0.0013 & \\
13 & INTP & 0.0096 & 2.3463 & 244.280 & 0.0011 & 0.0020 & \\
14 & KLBF & -0.0066 & -5.7357 & 865.340 & 0.0011 & -0.0032 & \\
15 & LPKR & -0.2019 & -0.8891 & 4.404 & 0.0011 & -0.0010 & \\
16 & LPPF & -0.0307 & -3.0164 & 98.104 & 0.0011 & -0.0030 & \\
17 & MNCN & -0.0146 & -0.9530 & 65.480 & 0.0011 & -0.0010 & \\
18 & PGAS & -0.0099 & -0.0258 & 2.615 & 0.0011 & 0.0000 & \\
19 & PWON & 0.0240 & 0.6136 & 25.562 & 0.0011 & 0.0007 & \\
20 & SMGR & 0.0058 & 1.3417 & 229.433 & 0.0011 & 0.0012 & \\
21 & SSMS & -0.0136 & -1.1155 & 82.062 & 0.0011 & -0.0011 & \\
22 & TLKM & -0.0051 & -1.8211 & 354.325 & 0.0011 & -0.0014 & \\
23 & UNTR & 0.0920 & 4.3079 & 46.804 & 0.0011 & 0.0045 & \\
24 & UNVR & 0.0072 & 6.9681 & 971.543 & 0.0011 & 0.0037 & \\
25 & WSKT & 0.0035 & 0.0866 & 24.756 & 0.0011 & 0.0001 & \\
\hline S4n & Das & & & & & \\
& &
\end{tabular}

Sumber: Data sekunder diolah, 2018

Kandidat Sekuritas yang Dapat Membentuk Portofolio Optimal

Tahap Keempat adalah menentukan kandidat sekuritas yang menjadi sampel penelitian yang akan dijadikan portofolio optimal dengan membandingkan nilai ERB dengan nilai $C^{*}$, yang dimana untuk menjadikan saham-saham pada sampel 
menjadi portofolio optimal ERB $\geq C^{*}$. Saham - saham yang menjadi kandidat dalam portofolio optimal ini dapat dilihat pada tabel 4 .

Tabel 4.

Saham Indeks IDX30 yang Dapat Membentuk Portofolio

\begin{tabular}{|c|c|c|c|c|c|}
\hline No & $\begin{array}{c}\text { Kode } \\
\text { Saham }\end{array}$ & Nama Saham & ERB & $\mathbf{C}^{*}$ & Keterangan \\
\hline 1 & ADHI & Adi Karya (Persero) Tbk & -0.0094 & 0.0127 & \\
\hline 2 & ADRO & Adaro Energy Tbk & 0.0803 & 0.0127 & Kandidat \\
\hline 3 & ASII & Astra Internasional Tbk & -0.0003 & 0.0127 & \\
\hline 4 & $\mathrm{BBCA}$ & Bank Central Asia (Persero) & 0.0224 & 0.0127 & Kandidat \\
\hline 5 & $\mathrm{BBNI}$ & $\begin{array}{l}\text { Bank Negara Indonesia } \\
\text { (Persero) Tbk }\end{array}$ & 0.0189 & 0.0127 & Kandidat \\
\hline 6 & BBRI & $\begin{array}{l}\text { Bank Rakyat Indonesia } \\
\text { (Persero) Tbk }\end{array}$ & 0.0177 & 0.0127 & Kandidat \\
\hline 7 & BMRI & Bank Mandiri (Persero) Tbk & 0.0191 & 0.0127 & Kandidat \\
\hline 8 & BSDE & Bumi Serpong Damai Tbk & -0.0087 & 0.0127 & \\
\hline 9 & GGRM & Gudang Garam Tbk & 0.0143 & 0.0127 & Kandidat \\
\hline 10 & HMSP & $\begin{array}{l}\text { Hanjaya Mandala Sampoerna } \\
\text { Tbk }\end{array}$ & 0.0102 & 0.0127 & \\
\hline 11 & ICBP & $\begin{array}{l}\text { Indofood CBP Sukses Makmur } \\
\text { Tbk }\end{array}$ & -0.0146 & 0.0127 & \\
\hline 12 & INDF & Indofood Sukses Makmur Tbk & -0.0044 & 0.0127 & \\
\hline 13 & INTP & $\begin{array}{l}\text { Inducement Tunggal Prakarsa } \\
\text { Tbk }\end{array}$ & 0.0096 & 0.0127 & \\
\hline 14 & KLBF & Kalbe Farma Tbk & -0.0066 & 0.0127 & \\
\hline 15 & LPKR & Lippo Karawaci Tbk & -0.2019 & 0.0127 & \\
\hline 16 & LPPF & Matahari Department Store Tbk & -0.0307 & 0.0127 & \\
\hline 17 & MNCN & Media Nusantara Citra Tbk & -0.0146 & 0.0127 & \\
\hline 18 & PGAS & $\begin{array}{l}\text { Perusahaan Gas Negara } \\
\text { (Persero) Tbk }\end{array}$ & -0.0099 & 0.0127 & \\
\hline 19 & PWON & Pakuwon Jati Tbk & 0.0240 & 0.0127 & Kandidat \\
\hline 20 & SMGR & Semen Indonesia (Persero) Tbk & 0.0058 & 0.0127 & \\
\hline 21 & SSMS & Sawit Sumbermas Sarana Tbk & -0.0136 & 0.0127 & \\
\hline 22 & TLKM & $\begin{array}{l}\text { Telekomunikasi Indonesia } \\
\text { (Persero) Tbk }\end{array}$ & -0.0051 & 0.0127 & \\
\hline 23 & UNTR & United Tractors Tbk & 0.0920 & 0.0127 & Kandidat \\
\hline 24 & UNVR & Unilever Indonesia Tbk & 0.0072 & 0.0127 & \\
\hline 25 & WSKT & Waskita Karya (Persero) Tbk & 0.0035 & 0.0127 & \\
\hline
\end{tabular}

Sumber: Data sekunder diolah, 2018 
Tabel 4. menunjukkan bahwa terdapat beberapa sekuritas yang memiliki nilai ERB lebih besar dibandingkan nilai $\mathrm{C}^{*}$, saham tersebut antara lain Adaro Energy Tbk (ADRO), Bank Central Asia (Persero) Tbk (BBCA), Bank Negara Indonesia (Persero) Tbk (BBNI), Bank Rakyat Indonesia (Persero) Tbk (BBRI), Bank Mandiri (Persero) Tbk (BMRI), Gudang Garam Tbk (GGRM), Pakuwon Jati Tbk (PWON), United Tractors Tbk (UNTR). Saham inilah yang dapat dimasukkan untuk membentuk portofolio optimal.

Proporsi Saham yang dapat Membentuk Portofolio Optimal.

Proporsi dana (Wi) dapat dihitung dengan cara membagi $\mathrm{Zi}$ dengan total $\mathrm{Zi}$ ( $\left.\sum \mathrm{Zi}\right) . \mathrm{Zi}$ dapat diperoleh dengan membagi beta $(\beta)$ dengan varian residu $\left(\sigma^{2}\right.$ ei) kemudian dikalikan dengan selisih excess return to beta dengan cut-off point (Ci). Hasil perhitungan proporsi dana masing-masing saham adalah sebagai berikut.

\section{Tabel 5.}

Proporsi Dana Portofolio Optimal Saham Indeks IDX30

\begin{tabular}{cccc}
\hline No & Kode Saham & $\mathbf{Z i}$ & $\mathbf{W i}$ \\
1 & ADRO & 2.9389 & $7.95 \%$ \\
2 & BBCA & 8.7650 & $23.72 \%$ \\
3 & BBNI & 2.9143 & $7.89 \%$ \\
4 & BBRI & 8.1370 & $22.02 \%$ \\
5 & BMRI & 4.9682 & $13.44 \%$ \\
6 & GGRM & 0.3965 & $1.07 \%$ \\
7 & PWON & 0.7100 & $1.92 \%$ \\
8 & UNTR & 8.1258 & $21.99 \%$ \\
& Total & 36.95571 & $100 \%$ \\
\hline
\end{tabular}

Sumber: Data sekunder diolah, 2018

Tabel 5, menunjukkan bahwa proporsi dana yang disumbangkan masingmasing sekuritas pembentuk portofolio optimal yaitu ADRO sebesar 7.95 persen, BBCA sebesar 23.72 persen, BBNI sebesar 7.89 persen, BBRI sebesar 22,02 
persen, BMRI sebesar 13.44 persen, GGRM sebesar 1.07 persen, PWON sebesar 1.92 persen, UNTR sebesar 21.99 persen.

Expected Return Portofolio dan Risiko Portofolio

Tingkat pengembalian harapan portofolio dapat dihitung dengan cara menjumlahkan alpa dan beta kemudian dikalikan dengan return market (return pasar), sedangkan risiko portofolio dapat dihitung dengan cara menjumlahkan risiko sistematik portofolio dengan risiko unik portofolio. Berikut merupakan hasil perhitungan expected return portofolio dan risiko portofolio.

Tabel 6.

Return Portofolio dan Risiko Portofolio Saham Indeks IDX30

\begin{tabular}{clcc}
\hline No & Kode Saham & $\mathbf{E}(\mathbf{R p})$ & $\boldsymbol{\sigma}^{2} \mathbf{p}$ \\
1 & ADRO & 0.0041 & 0.0000887 \\
2 & BBCA & 0.0060 & 0.0001168 \\
3 & BBNI & 0.0024 & 0.0000316 \\
4 & BBRI & 0.0063 & 0.0001478 \\
5 & BMRI & 0.0031 & 0.0000439 \\
6 & GGRM & 0.0002 & 0.0000005 \\
7 & PWON & 0.0003 & 0.0000025 \\
8 & UNTR & 0.0102 & 0.0002269 \\
& Total & $\mathbf{0 . 0 3 2 5}$ & $\mathbf{0 . 0 0 0 6 5 8 7}$ \\
\hline
\end{tabular}

Sumber: Data sekunder diolah, 2018

Dilihat dari tabel 6, portofolio optimal yang dibentuk oleh beberapa saham Indeks IDX30 antara lain ADRO, BBCA, BBNI, BBRI, BMRI, GGRM, PWON, UNTR memperoleh expected return portofolio sebesar 3.25 persen, sedangkan risiko portofolio yang kemungkinan akan diperoleh yaitu sebesar 0,07 persen. 


\section{PEMBAHASAN}

Berdasarkan hasil perhitungan portofolio optimal yang telah dilakukan menggunakan pendekatan model indeks tunggal sebelumnya didapatkan hasil bahwa dari 25 saham yang tergabung dan digunakan sebagai sampel penelitian dalam Indeks IDX30 periode Agustus 2016-Januari 2018 terdapat 13 saham yang dapat membentuk sebuah portofolio optimal, saham-saham tersebut antara lain Adaro Energy Tbk (ADRO), Bank Central Asia (Persero) Tbk (BBCA), Bank Negara Indonesia (Persero) Tbk (BBNI), Bank Rakyat Indonesia (Persero) Tbk (BBRI), Bank Mandiri (Persero) Tbk (BMRI), Gudang Garam Tbk (GGRM), Hanjaya Mandala Sampoerna Tbk (HMSP), Indocement Tunggal Prakarsa Tbk (INTP), Pakuwon Jati Tbk (PWON), Semen Gresik Indonesia Tbk (SMGR), United Tractor Tbk (UNTR), Unilever Indonesia Tbk (UNVR) dan Waskita Karya (WSKT).

Proporsi dana saham yang dapat membentuk portofolio optimal dapat dilihat pada Gambar 1.

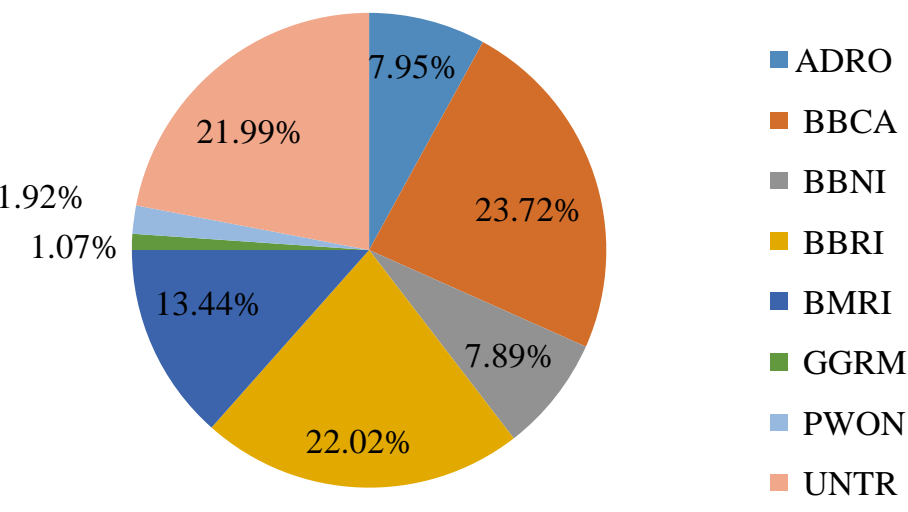

\section{Gambar 1. Proporsi Dana Masing-Masing Saham Pembentuk Portofolio} Sumber :Data sekunder diolah, 2018 
Gambar 1 menunjukkan besarnya proporsi dana yang disumbangkan oleh masing-masing saham untuk dapat membentuk portofolio optimal, antara lain. ADRO sebesar 7.95 persen, BBCA sebesar 23.72 persen, BBNI sebesar 7.89 persen, BBRI sebesar 22,02 persen, BMRI sebesar 13.44 persen, GGRM sebesar 1.07 persen, PWON sebesar 1.92 persen, UNTR sebesar 21.99 persen. Expected return portofolio yang dihasilkan oleh saham-saham pembentuk portofolio optimal yaitu sebesar 3.25 persen dengan risiko yang akan diterima sebesar 0,07 persen.

Menurut Triharjono (2013) menggabungkan sekelompok sekuritas dalam suatu wadah yang disebut portofolio dapat menurunkan risiko yang mungkin dihadapi investor dibandingkan dengan saham ditransaksikan secara individual. Pada tabel berikut terdapat perbandingan antara apabila sekuritas digabungkan dalam suatu portofolio dengan sekuritas yang ditransaksikan secara individu.

Tabel 7.

Return Portofolio dan Risiko Portofolio Saham Indeks IDX30

\begin{tabular}{cccc}
\hline NO & NAMA SAHAM & $\boldsymbol{\Sigma i}$ & $\boldsymbol{\sigma}^{2} \mathbf{p}$ \\
1 & ADRO & 0.1185 & 0.0000887 \\
2 & BBCA & 0.0463 & 0.0001168 \\
3 & BBNI & 0.0723 & 0.0000316 \\
4 & BBRI & 0.0564 & 0.0001478 \\
5 & BMRI & 0.0501 & 0.0000439 \\
6 & GGRM & 0.0637 & 0.0000005 \\
7 & PWON & 0.0817 & 0.0000025 \\
8 & UNTR & 0.0686 & 0.0002269 \\
& TOTAL & 0.5576 & $\mathbf{0 . 0 0 0 6 5 8 7}$ \\
& RISIKO & $\mathbf{5 5 . 7 6 \%}$ & $\mathbf{0 . 0 7 \%}$ \\
\hline
\end{tabular}

Sumber: Data sekunder diolah, 2018 
Tabel 7 menunjukkan hasil bahwa apabila investor berinvestasi pada saham individual maka investor akan mendapatkan risiko yang besar, sedangkan apabila investor membentuk sebuah portofolio investor bisa memperkecil risikonys dari risiko total investasi di sekuritas tunggal didapatkan sebesar 55,76 persen sedangkan apabila membentuk sebuah portofolio investor bisa memperkecil risikonya sebesar 55.69 persen sehingga risiko portofolio yang diterima sebesar 0.07 persen..

Jadi dapat disimpulkam bahwa, apabila investor ingin mendapatkan return yang maksimal dengan risiko yang minimum, investor dapat melakukan investasi dengan membentuk sebuah portofolio, karena dengan portofolio nantinya risiko yang akan diperoleh investor lebih kecil dibandingkan dengan investor melakukan investasi di saham individual.

\section{SIMPULAN DAN SARAN}

Berdasarkan hasil serta pembahasan di atas, dapat ditarik kesimpulan sahamsaham yang dapat membentuk kombinasi portofolio optimal berdasarkan model indeks tunggal pada saham-saham Indeks IDX30 Periode Agustus 2016-Januari 2018 sebanyak 13 saham, yaitu saham ADROdengan proporsi dana sebesar 7.95 persen, BBCA23.72 persen, BBNI7.89 persen, BBRI 22.02 persen, BMRI 13.44 persen, GGRM1.07 persen, PWON 1,92 persen, UNTR 21.99 persen.

Return Ekspetasi (Expected Return) portofolio yang diperoleh dari pembentukan portofolio optimal pada saham yang tergabung dalam Indeks IDX30 periode Agustus 2016-Januari 2018 yaitu sebesar 3,25 persen dengan risiko portofolio sebesar 0.07 persen. 
Berdasarkan hasil penelitian yang telah dilakukan saran yang dapat diberikan adalah bagi Investor yang ingin berinvestasi tapi ingin mendapatkan risiko yang kecil dengan menggunakan saham-saham dalam Indeks IDX30, investor dapat melakukan investasi dengan cara membentuk sebuah portofolio dan menginvestasikan dananya sesuai dengan proporsi dana yang terbentuk dari penelitian, dimana saham ADRO diproporsikan dananya sebesar 7.95 persen, BBCA 23.72 persen, BBNI 7.89 persen, BBRI 22.02 persen, BMRI 13.44 persen, GGRM 1.07 persen, PWON 1,92 persen, UNTR 21.99 persen.. Portofolio optimal ini juga menawarkan keuntungan tingkat pengembalian dimasa datang (expected return) sebesar 3.25 persen, dan dengan risiko portofolio yang kecil yaitu sebesar 0,07 persen. (2). Bagi peneliti selanjutnya, disarankan menggunakan pendekatan Markowits dan berbagai indeks lainnya ataupun berbagai sektor yang ada di Bursa Efek Indonesia (BEI) dalam pembentukan portofolio optimalnya dan juga mampu untuk memberikan perbandingan indeks atau sektor mana saja yang memberikan tingkat return dan risiko yang terbaik. 


\section{REFERENSI}

Agmiviolya, Youvia Clara., M. Dzulkirom AR., \&R.Rustam Hidayat. (2014). Analisis Portofolio dengan Single Index Model dalam Upaya Meminimalisir Risiko Investasi Pasar Modal (Studi Pada Perusahaan Sektor Food and Beverages yang Listing di Bursa Efek Indonesia Periode 2011-2013. Jurnal Administrasi Bisnis (JAB), 13(1), 1-8.

Andrade, Pratiba Jenifer. (2012). Construction of Optimal Portfolio of Equity, using Sharpe's Single Index Model: A Case Study of IT Sector. International Journal of Applied Financial Management Perspective, 1(2), 86-88.

Ariasih, Ni Luh Putu Ika dan I Ketut Mustanda. (2018). Pembentukan Portofolio Optimal Menggunakan Model Indeks Tunggal Pada Saham Indeks LQ45. EJournal Manajemen Unud. 7(8), 4508-4538.

Darmitha, Surya dan I.B Anom Purbawangsa. (2016). Study Komparatif Kinerja Portofolio Optimal Saham LQ45 Dan 50 Most Active Stocks By Trading Frequency. E-Journal Manajemen Unud, 5(11), 7185-7213.

Gautam, J., \& Singh, S. (2014). The Single Index Model \& the Construction of Optimal Portfolio: A Case of Banks Listed on NSE India. Ssrn, 4(2), hal.110-115.

Giri, Laxmi Kanta and Gayadar Parhi. (2017). Optimum Portfolio Construction Using Single Index Model. Intercontinental Journal Of Finance Research Review, 5(2), 2347-1654.

Gopalakrishnan, M.Muthu. (2014). Optimal Portofolio Selection Using Sharpe's Single Index Model. Indian Journal Of Applied Research, 4(1), 286-288.

Gunawan, Olivia Veronika \& Luh Gede Sri Artini. (2016) Pembentukan Portofolio Optimal Dengan Pendekatan Model Indeks Tunggal pada Saham LQ-45 di Bursa Efek Indonesia. E-journal Manajemen Unud, 5(9), 55545584.

Hartono, Jogiyanto. (2016).Teori Portofolio dan Analisis Investasi, Edisi Kesepuluh. Yogyakarta : BPFE UGM.

Kumar D, Deepak. (2013). Optimum Portfolio (Banking Sector) Construction Using Sharpe Single Index Model. IJEMR, 3(8), 2249-2585

Mary, J. F., \& Rathika, G. (2015). The Single Index Model and the Construction of Optimal Portfolio With CNX Pharma Scrip. International Journal Of Management (IJM), 6(1), 87-96. 
Meman, Mahammadrafique U. (2015). Optimal Equity Portfolio Construction by using Sharpe Single Index Model with reference to the BSE-30 (Bombay Stock Exchange) Securities. Global Journal For Research Analysis, 4(12), 2277-8160.

Nalini, R., (2014). Optimal Portfolio Construction Using Sharpe's Single Index Model - A Study Of Selected Stocks From BSE. International Journal of Advanced Research in Management and Social Sciences, 3(12), 72-93.

Nandan, Tanuj.,\&Nivedita Srivastava. (2017). Construction of Optimal Portfolio Using Sharpe's Single Index Model: An Empirical Study on Nifty 50 Stocks. Journal of Management Research and Analysis, 4(2), 74-83.

Poornima, S., \& Remesh, A.P. (2015). Construction of Optimal Portofolio Using Sharpe's Single Index Model: A Study with Reference to Banking \& IT Sector. International Journal of Applied Research. 1(13), 21-24.

Qur'anitasari., Raden Rustam Hidayat., \&Sri Sulasmiyati. (2016). Analisis Pembentukan Portofolio Optimal Dalam Meminalkan Tingkat Risiko Investasi Dengan Menggunakan Model Indeks Tunggal (Studi Kasus Saham LQ-45 Di Bursa Efek Indonesia Periode Januari 2013-Juli 2015). Jurnal Administrasi Bisnis. 21(1), 140-149

Rahmasita, Fajarayu., R.Rustam Hidayat.,\& Devi Farah Azizah. (2014). Pembentukan Portofolio Optimal dengan Menggunakan Single Index Model (Studi Pada Saham-saham Sektor Industri Dasar dan Kimia Bursa Efek Indonesia periode 2011-2013). Jurnal Administrasi Bisnis, 16(1), 1-10.

Raju, Guntur Arjana.,\&Mrunali Jambotkar. (2018). Optimal portfolio construction in stock markets: Evidence from Indian Blue Chip Stocks. International Journal Of Research Culture Society, 2(1), 2456-6683.

Ramadhan, R. D. (2014). Analisis Pemilihan Portofolio Optimal Dengan Model Dan Pengembangan Dari Portofolio Markowitz (Studi Pada Indeks Bisnis 27 Di Bursa Efek Indonesia Periode 2011 - 2013). Jurnal Administrasi Bisnis (JAB), 14(1), 1-10.

Shah, C. A. (2015). Construction of Optimal Portfolio Using Sharpe Index Model \& Camp for BSE Top 15 Securities. IJRAR- International Journal of Research and Analytical Reviews, 2(2), 168-178.

Shah, Tirtank (2014). Constructing Optimal Portfolio: Sharpe's Single Index Model. SSRN-Social Science Research Network, 1-14.

Subashree, S \&Bhoopal, M. (2017). Construction Of Optimal Portfolio Using Sharpe's Single Index Model - A Study With Reference To Banking And Automobile Sectors. Asia Pacific Journal of Research, 1(57), 2347-4793. 
Supriyanthi, Ni Ketut Diah, \& Henny Rahyuda. (2017). Pembentukan Portofolio Optimal Pada Saham-Saham Indeks Bisnis 27 Dengan Menggunakan Model Indeks Tunggal. E-Journal Manajemen Unud, 6(11), 6216-6240.

Suroto. (2015). Analisis Portofolio Optimal Menurut Model Indeks Tunggal (Studi Empiris Pada Saham LQ 45 di Bursa Efek Indonesia Periode Agustus 2012-Juli 2015). Media Ekonomi dan Manajemen, 30(2), 161-177.

Syamni, Ghazali \& Al Muntasir. (2013) Optimal Portfolio Analysis Using Single Index Model In The LQ-45 Index In Indonesia Stock Exchange. In: International Conference, UNISBANK, Semarang.

Tandelin, Eduardus. (2010). Portofolio dan Investasi Teori dan Aplikasi, Edisi Pertama Cet Kelima, Yogyakarta: KANISIUS.

Triharjono, S. (2013). Single Index Model Sebagai Alat Analisis Optimalisasi Portofolio Investasi Saham (Studi Kasus Pada Kelompok Saham LQ-45 Di Bei Tahun 2009-2011 ). Jurnal Ilmu Mnajaemen \& Bisnis, 4(1), 1-12.

Utamayasa, Komang Nehru, \& Ni Luh Putu Wiagustini. (2016). Penentuan Portofolio Optimal Dengan Menggunakan Model Indeks Tunggal Pada Saham Perbankan Di Bursa Efek Indonesia. E-Journal Manajemen Unud, 5(6), hal.3905-3933.

Wibowo, Windy Martya., Sri Mangesti Rahayu., \&Maria Goretti Wi Endang N.P. (2014). Penerapan Model Indeks Tunggal Untuk Menetapkan Komposisi Portofolio Optimal (Studi Pada Saham-Saham LQ 45 Yang Listing Di Bursa Efek Indonesia (BEI) Tahun 2010-2012). Jurnal Administrasi Bisnis (JAB), 9(1), 1-9.

Zubir, Zalmi. (2011). Manajemen Portofolio Penerapan Dalam Investasi Saham. Jakarta: Salemba Empat.

www.bi.go.id (Diakses pada 21 Juni 2018)

www.finance.yahoo.com (Diakses pada 15 Juni 2018)

www.idx.co.id (Diakses pada 15 Juni 2018). 